\title{
REICH E O MOVIMENTO DE HIGIENE MENTAL ${ }^{1}$
}

\author{
Paulo Albertini* \\ Flávia Zanni Siqueira\# \\ Luciano Aparecido Tomé \\ Tânia Lisboa Machado ${ }^{\infty}$
}

\begin{abstract}
RESUMO. Este estudo visa investigar se a atuação do psicanalista dissidente Wilhelm Reich no cenário científico-cultural da primeira metade do século passado permite associá-lo ao movimento de higiene mental. A fim de cumprirmos tal objetivo, duas direções de pesquisa foram assumidas. A primeira envolveu escritos sobre as origens e as orientações definidoras da moderna saúde pública, do higienismo e, em especial, do movimento de higiene mental. A segunda diz respeito a um levantamento na obra reichiana - artigos, livros, capítulos de livros, cartas e entrevistas - de forma a observar: a) referências diretas ao movimento de higiene mental; b) análises ou relatos de ações do autor vinculadas a esse movimento; c) uso de linguagem característica de tal movimento. Como conclusão, foram formuladas linhas de entendimento sobre a participação de Reich no cenário científico-cultural da primeira metade do século passado, no que tange à associação desse autor com o movimento de higiene mental..
\end{abstract}

Palavras-chave: Wilhelm Reich, higiene mental, psicanálise.

\section{REICH AND THE MENTAL HYGIENE MOVEMENT}

\begin{abstract}
This essay takes two different research directions in order to investigate if the actions of the dissident psychoanalyst Wilhelm Reich, in the cultural-scientific scenario of the first half of the twentieth century, allow us to associate him to the mental hygiene movement. One of the research directions is a review of some writings about the origins and the defining orientations of modern public health care, hygienism and especially the mental hygiene movement. The second one concerns a referring to Reich's work - articles, books, chapters, letters and interviews - aiming to observe: a) direct references to the mental hygiene movement; b) analyses or accounts of the author's actions linked to this movement; c) usages of its characteristic vocabulary. As a conclusion, understanding guidelines about Reich's participation in the cultural-scientific scenario of the first half of the twentieth century, regarding to the mental hygiene movement, were formulated.
\end{abstract}

Key words: Wilhelm Reich, mental hygiene, psychoanalysis.

\section{REICH Y EL MOVIMIENTO DE HIGIENE MENTAL}

RESUMEN. Este estudio tiene como objetivo el de investigar si la actuación del psicoanalista disidente Wilhelm Reich en el escenario científico-cultural de la primera mitad del siglo pasado permite asociarle al movimiento de higiene mental. Para cumplir con ese objetivo, la investigación ha tomado dos direcciones: por la primera se ocupa de escritos sobre los orígenes y las orientaciones definidoras de la moderna salud pública, del higienismo y, en especial, del movimiento de higiene mental. Por la segunda se hace una lectura de la obra reichiana - artículos, libros, capítulos de libros, cartas y entrevistas - de manera a observar: a) referencias directas al movimiento de higiene mental; b) análisis o relatos de acciones del autor relacionadas a ese movimiento; c) uso de lenguaje característico del movimiento. Como conclusión, se formularon líneas de entendimiento sobre la participación de Reich en el escenario científico-cultural de la primera mitad del siglo pasado, en lo que respecta a la asociación de ese autor con el movimiento de higiene mental.

Palabras-clave: Wilhelm Reich, higiene mental, psicoanálisis.

1 O presente trabalho é fruto do projeto de pesquisa Reich, o movimento de higiene mental e a educação, do Grupo de Estudos de História da Psicologia Aplicada à Infância (GEPHAI), vinculado ao Programa de Pós-graduação em Psicologia Escolar e do Desenvolvimento Humano do Instituto de Psicologia da Universidade de São Paulo.

* Psicólogo. Doutor. Professor do Instituto de Psicologia da Universidade de São Paulo-USP.

\# Discente do Instituto de Psicologia da Universidade de São Paulo-USP.

II Psicólogo pelo Instituto de Psicologia da Universidade de São Paulo-USP.

æ Discente do Instituto de Psicologia da Universidade de São Paulo-USP. 
O psicanalista Wilhelm Reich (1897-1957) participou ativamente do cenário científico-cultural na primeira metade do século passado. No Dicionário de Psicanálise de Roudinesco e Plon (1998), no parágrafo que inaugura a exposição sobre Reich, os autores o descrevem como o "maior dissidente da segunda geração freudiana ${ }^{2}$ " (p. 650) e como:

o criador do freudo-marxismo, o teórico de uma análise do fascismo que marcou todo o século e o artífice de uma reformulação da técnica psicanalítica que se apoiava em uma concepção da sexualidade mais próxima da sexologia que da psicanálise (p. 651).

Já na literatura mais especificamente dedicada ao estudo da obra de Reich, os seguintes pontos costumam ser destacados: foi organizador $\mathrm{e}$ formulador de diretrizes para o desenvolvimento da técnica psicanalítica; pioneiro no campo das psicoterapias corporais; crítico incansável da repressão sexual e pensador da revolução sexual; propositor de uma série de idéias endereçadas ao domínio da educação; militante comunista nos anos finais da década de 1920 e início dos anos 1930; pesquisador da energia orgone.

Porém, a nosso ver, essas distinções usuais não contemplam um aspecto relevante da trajetória reichiana: o possível envolvimento desse autor com o movimento de higiene mental. Esse tema, até onde sabemos, não tem sido abordado nas pesquisas sobre a obra reichiana e tampouco nas investigações dedicadas ao estudo do higienismo. Assim, este trabalho, reconhecendo essas lacunas, procura investigar se Reich pode ser associado ao movimento de higiene mental e, com isso, contribuir para aprofundar o conhecimento a respeito das idéias e ações desse psicanalista militante na área da saúde pública, além de ampliar os achados sobre o higienismo e sua história, especialmente no campo da saúde mental.

Para cumprirmos tal objetivo, duas linhas de investigação foram assumidas. A primeira envolveu escritos sobre as origens e as orientações definidoras da moderna saúde pública, do higienismo e, em especial, do

2 Entre outros, composta por Ernst Kris, Heinz Hartmann, Rudolph Loewenstein, Wilhelm Reich, Otto Fenichel e Melanie Klein. De acordo com Roudinesco e Plon (1998, p. 293), essa geração: a) começou a se formar a partir de 1918 ; b) enfrentou a ascensão do nazismo, o que a forçou ao exílio; c) teve como vínculo fundamental a IPA, e não uma cidade ou um mestre; d) transformou a doutrina original a partir de uma leitura centralizada na segunda tópica. movimento de higiene mental. A segunda diz respeito a um amplo levantamento na obra reichiana - artigos, livros, capítulos de livros, cartas e entrevistas - de forma a observar: a) referências diretas ao movimento de higiene mental; b) análises ou relatos de ações do autor vinculadas a esse movimento; c) uso de linguagem característica de tal movimento.

A exposição deste estudo foi organizada em três conjuntos: no primeiro, o leitor encontrará uma caracterização do movimento de higiene mental; no segundo, os achados a respeito da participação de Reich nesse movimento; no terceiro, algumas considerações finais.

\section{O MOVIMENTO DE HIGIENE MENTAL}

Para apreendermos o contexto social em que nasceu o movimento de higiene mental, faz-se necessária uma breve incursão histórica pela área da saúde pública. Comecemos por lembrar que um dos efeitos do processo de industrialização foi uma corrida em direção às grandes cidades, que acarretou um brutal adensamento populacional urbano. De acordo com a detalhada exposição histórica de Rosen (1994), Londres, por exemplo, que contava com 958.000 habitantes em 1801, passou a 1.948.000 habitantes em 1831. Nessas cidades inchadas, a população pobre grande maioria - vivia em péssimas condições de moradia, saneamento básico e alimentação, e era submetida a extenuantes jornadas de trabalho, inclusive as mulheres e crianças. $\mathrm{O}$ resultado dessa alta concentração de pessoas vivendo em precárias condições de higiene foi a disseminação de uma série de doenças, como cólera, varíola, sarampo, escarlatina, difteria, febre tifóide, lepra, escorbuto, tuberculose, entre outras. (Rosen, 1994).

Diante desse quadro, surgiu na Inglaterra, primeiro país a se industrializar, a moderna saúde pública: era uma medida que procurava organizar o caos que vigorava em tudo que dizia respeito à saúde das populações pobres das grandes cidades industriais. Essa modalidade da esfera médica, com o entendimento de que a ampla disseminação de doenças estava ligada tanto às condições de saneamento básico quanto aos hábitos pessoais, vai atuar no sentido da modificação dos aspectos sociais e pessoais potencialmente patogênicos. Em outras palavras, a meta não era curativa, mas preventiva.

Como se vê, a moderna atividade da saúde pública nasce em decorrência dos problemas surgidos com a revolução industrial e, além disso, tem duas marcas fundamentais: uma extrema dependência das políticas públicas para alcançar seus objetivos de 
melhoria na situação do saneamento das cidades, e uma forte ligação com a área da educação, de forma a favorecer a presença de comportamentos considerados higiênicos. Contudo, segundo a pertinente análise de Boarini (2003), a fim de desviar a atenção das precárias condições concretas em que vivia a classe trabalhadora, fator, em última instância, determinante da alta incidência de doenças, passou-se a difundir a idéia de que o problema poderia ser revolvido pela educação higiênica. Assim a autora registra esse uso ideológico da educação: "a educação higiênica passa a ser entendida como a redenção dessa lúgubre situação, vivida pela classe trabalhadora. Constituem-se, assim, as grandes cruzadas em prol da higiene: higiene escolar, higiene social, puericultura, higiene mental, educação física, educação sanitária etc.” (p. 35-36).

No que diz respeito especificamente à área da saúde mental, de acordo com o relato de Desviat (1999), o movimento voltado à higiene mental iniciou-se nos Estados Unidos, impulsionado pela publicação, em 1908, do livro A mente que encontrou a si mesma, escrito por um ex-paciente psiquiátrico, Clifford W. Beers. Nesse texto, que comoveu a opinião pública, o autor denunciou a precariedade do atendimento prestado pelos asilos psiquiátricos e defendeu "a passagem do atendimento individualizado por prazo determinado para um atendimento dirigido a toda a comunidade e por prazo indefinido, identificando os objetivos da psiquiatria com os da saúde pública” (Desviat, 1999, p. 57). Em 1909, um ano após a publicação do relato de Beers, concretizando a aproximação da psiquiatria com a saúde pública, fundouse, em Nova York, o Comitê Nacional de Higiene Mental e, então, entidades semelhantes foram sendo organizadas pelo mundo. Em 1930, contando com representantes de 52 países, realizou-se na cidade de Washington o I Congresso Internacional de Higiene Mental.

Para Rosen (1994), no início, a ação pela higiene mental teve como propósito a melhoria das condições de atendimento ao doente mental e, para isso, denunciava as condições apavorantes dos asilos psiquiátricos e investia na ampliação das formas de atenção a esses pacientes. $\mathrm{Na}$ seqüência, o foco do movimento, de acordo com a perspectiva sanitarista, ampliou-se da assistência ao enfermo para uma possível atuação preventiva. O autor registra, porém, que um grave problema se configurou: a dificuldade em estabelecer critérios definidores de saúde e de doença.

Devido a essa séria limitação quanto aos critérios, na prática, o que se observou foi que, em linhas gerais, a busca por uma ação preventiva no domínio das doenças psíquicas acabou por suscitar a produção de um saber que freqüentemente visava a mera adaptação social. Alguns exemplos desse resultado podem ser observados no livro Guia da saúde mental, de um psiquiatra com reconhecida atuação nos campos da higiene mental e da avaliação psicológica, Emilio Mira y Lopes. Nesse trabalho, no tópico intitulado Psico-higiene do adolescente, pode-se ler:

O maior desejo do adolescente masculino normal é de conquistar o prestígio social, baseando-se na sua força, sua coragem e sua independência. Ao contrário, a moça adolescente anseia conseguir esse prestígio com base no seu encanto, sua graça e sua suavidade. Dessa maneira a diferenciação psico-sexual imprime uma diferença de atitudes e de estilos vitais na adolescência, e, à medida em que estas se atenuam ou confundem, surge o perigo de condutas duvidosas ou conflitivas (1956/1961, p. 90).

Talvez pareça desnecessário apontar que essas noções de adolescente masculino e adolescente feminino referem-se apenas a determinados tipos psicológicos usuais, os quais, ao contrário do que sugere o texto, não deveriam servir como critérios de normalidade. Mas há diversos outros excertos desse guia de saúde mental que permitem verificar o modo como, com a chancela da ciência, um "tipo psicológico ordinário" (Costa, 1984, p. 73) de determinado contexto sócio-histórico é elevado à categoria de padrão sadio e desejável.

Por fim, como o intuito desta parte do trabalho é caracterizar o movimento de higiene mental, não podemos concluí-la sem lançar luz sobre uma corrente de pensamento que muito influenciou o campo científico nas últimas décadas do século XIX e primeiras do século XX. Estamos nos referindo à eugenia.

De acordo com Schwarcz (1993, p. 60) "o termo 'eugenia' - eu: boa; genus: geração - foi criado pelo cientista britânico Francis Galton [...] na época conhecido por seu trabalho como naturalista e como geógrafo especializado em estatística" ${ }^{3}$. Defendendo a tese de que as capacidades humanas deveriam ser atribuídas à hereditariedade e não à educação, em 1869 Galton publicou Hereditary genius, livro considerado fundador da eugenia. Assim Schwarcz (1993) analisa a marcante presença dessa orientação de pensamento:

Transformada em um movimento científico e social vigoroso a partir dos anos 1880 , a

Cabe registrar que a proposta de promover o aperfeiçoamento do homem como espécie não surgiu com a eugenia de Francis Galton. No trabalho de Boarini (2003), o leitor pode encontrar uma série de referências a essa visão desde o século VI a.C. 
eugenia cumpria metas diversas. Como ciência, ela supunha uma nova compreensão das leis da hereditariedade humana, cuja aplicação visava à produção de 'nascimentos desejáveis e controlados'; enquanto movimento social, preocupava-se em promover casamentos entre determinados grupos e - talvez o mais importante desencorajar certas uniões consideradas nocivas à sociedade (p. 60).

Para os objetivos deste estudo, o importante é salientar a presença de idéias eugenistas no campo da medicina e no das ciências humanas em geral (psicologia, sociologia, pedagogia etc.). Sobre a área médica, Foucault afirma que a medicina do final do século XIX "pretendia assegurar o vigor físico e a pureza moral do corpo social, prometia eliminar os portadores de taras, os degenerados [...] Em nome de uma urgência biológica e histórica, justificava os racismos oficiais, então iminentes. $\mathrm{E}$ os fundamentava como "verdade"" (Foucault, 1980, p. 54).

Um exemplo flagrante da penetração do pensamento eugenista no campo da higiene mental, com suas conseqüências racistas, ocorreu na jovem e mestiça nação brasileira. Costa (1980), investigando o pensamento psiquiátrico produzido por integrantes da Liga Brasileira de Higiene Mental - instituição fundada em 1923, no Rio de Janeiro, pelo psiquiatra Gustavo Riedel - observou que os psiquiatras tendiam

a confundir ou, pelo menos, a associar indevidamente os problemas psiquiátricos aos problemas culturais em geral. Para eles, os fenômenos psíquicos e culturais explicavam-se, unicamente, pela hipótese de uma causalidade biológica que, por sua vez, justificava a intervenção médica em todos os níveis da sociedade (p. 24).

Em suma, neste tópico visitamos o nascimento da moderna saúde pública na Inglaterra do início do século XIX, registrando seus objetivos de prevenção, sem deixar de mencionar o uso ideológico da educação nessa área. Depois, tratamos do nascimento do laço entre a psiquiatria e a saúde pública, do qual decorreu o movimento de higiene mental - com sua origem voltada para a melhoria das condições de atendimento psiquiátrico nos Estados Unidos, a adoção de uma orientação preventiva e, com isso, a constatação de um problema relativo ao estabelecimento de critérios definidores de saúde e de doença. Por fim, ao mencionarmos o caso da realidade brasileira, mostramos o enorme risco de trilhar um caminho meramente adaptativo nesse campo e registramos a forte presença do pensamento eugênico, com seu matiz de reducionismo biológico e racistas, no domínio da higiene mental.

Assim, tendo delineado uma caracterização desse movimento, passaremos a focalizar a relação de Reich com esse conjunto de noções e práticas.

\section{REICH E A PERSPECTIVA PREVENTIVA NA ÁREA DA SAÚDE MENTAL}

Em 1952, portanto cinco anos antes de sua morte, Reich foi entrevistado pelo psicanalista Kurt Eissler, representante dos Arquivos Sigmund Freud, entidade da Associação Psicanalítica Internacional. Nessa entrevista, publicada no livro Reich fala de Freud (Higgins \& Raphael, 1979), a certa altura o entrevistador formula a seguinte questão: "Dr. Reich, gostaria de interrogá-lo acerca do movimento de higiene mental no qual desempenhou um papel tão importante. Penso mesmo que lhe deu origem" (p. 79). Em resposta, Reich asseverou:

\begin{abstract}
Não, não dei origem à idéia do movimento de higiene mental ou ao fato dos movimentos de higiene mental. A única coisa que eu de fato introduzi foi o problema da prevenção das neuroses de massas. Há muito tempo que havia um movimento de higiene mental, mas o reconhecimento das neuroses como um problema social, neuroses de massas, foi o que introduzi no movimento de higiene mental (p. 79).
\end{abstract}

Chama a atenção nesse trecho da entrevista tanto o conteúdo da pergunta - a suposição de Eissler de que Reich teria dado origem ao movimento de higiene mental - quanto a resposta do entrevistado, atestando que teria introduzido no referido movimento "o problema da prevenção das neuroses de massas" e "o reconhecimento das neuroses como um problema social, neuroses de massas". Afinal, com o material bibliográfico de que dispomos hoje, é realmente possível associar Reich ao movimento de higiene mental? Se sim, em que termos? A fim de buscarmos respostas para isso, retrocedamos aos primeiros anos da participação de Reich na psicanálise.

Quando foi formalmente aceito como membro da Associação Psicanalítica Internacional em 1920, aos 23 anos, Reich era ainda aluno de medicina na Universidade de Viena. Na psicanálise, logo de início, interessou-se pelo atendimento da população pobre. Sobre esse assunto, segundo seu próprio relato (Reich, 1942/1978), em 1918, no congresso psicanalítico de Budapeste, Freud apontou para a necessidade de 
fundar clínicas destinadas a atender pessoas que não podiam pagar por um tratamento psicanalítico convencional e indicou que, nessas clínicas, a psicanálise deveria ser mesclada com a terapia por sugestão. Em 1920, sob a direção de Karl Abraham, uma clínica nesses moldes foi criada em Berlim. Dois anos depois, em 1922, ano de sua formatura, uma outra foi fundada em Viena, na qual Reich trabalhou por oito anos, "desde o dia da sua abertura [até], no fim, como diretor eleito" (p. 72). Vejamos uma comovente descrição reichiana do cotidiano na Clínica Psicanalítica de Viena:

Os horários de consulta viviam apinhados de gente. Havia industriários, funcionários de escritórios, estudantes e trabalhadores rurais. A afluência era tão grande que nós não dávamos conta, sobretudo depois que a clínica se tornou conhecida entre o povo. Cada psicanalista concordou em oferecer gratuitamente uma sessão diária. Mas não foi o suficiente. Precisávamos destacar os casos mais passíveis de análise. Isso nos obrigou a procurar descobrir os meios de avaliar as possibilidades de tratamento. Mais tarde, convenci os analistas a dar uma contribuição mensal [...] Uma coisa se tornou logo clara: $a$ psicanálise não é uma terapia para aplicação em massa. A idéia de prevenir neuroses não existia - e ninguém sabia o que dizer a respeito (p. 72/73). [itálicos originais]

Desse modo, ficamos sabendo que, para o jovem psicanalista com profunda preocupação social (Reich, 1990), a experiência nessa clínica psicanalítica popular, além de revelar os limites do atendimento individual convencional, trouxe o tema da prevenção da neurose.

Enquanto se envolvia com essa forma de trabalho clínico, Reich, no plano teórico, foi se afinando com uma série de noções psicanalíticas relacionadas ao chamado ponto de vista econômico ${ }^{4}$ - como, por exemplo, os conceitos de estase da libido e de neurose atual - e com uma determinada orientação freudiana, expressa principalmente no artigo Moral sexual 'civilizada' e doença nervosa moderna (Freud, 1908/1974), que avaliava de maneira crítica a moral sexual vigente, atribuindo-lhe uma parcela de responsabilidade pelo aumento das então chamadas

4 De acordo com Laplanche e Pontalis, o ponto de vista econômico "qualifica tudo o que se refere à hipótese segundo a qual os processos psíquicos consistem na circulação e repartição de uma energia quantificável (energia pulsional), isto é, susceptível de aumento, de diminuição, de equivalência" (1967/1983, p. 167). doenças nervosas. Além disso, segundo nossa interpretação (Albertini, 2005), Reich adota uma tese básica desse texto freudiano, aquela que concebe o comportamento sexual do homem como o protótipo de suas demais reações na vida. Nas palavras de Freud:

\begin{abstract}
O comportamento sexual de um ser humano freqüentemente constitui o protótipo de suas demais reações ante a vida. Do homem que mostra firmeza na conquista do seu objeto amoroso, podemos esperar que revele igual energia e constância na luta pelos seus outros fins. Mas se, por uma série de motivos, ele renuncia à satisfação de seus fortes instintos sexuais, seu comportamento em outros setores da vida será, em vez de enérgico, conciliatório e resignado (1908/1974, p. 203). [itálicos originais]
\end{abstract}

Esse caminho, que vislumbra no comportamento sexual o protótipo das reações humanas, contém uma orientação crítica frente à moral sexual do período e focaliza os fenômenos a partir de uma ênfase no ponto de vista econômico da psicanálise, presente em escritos mais iniciais da bibliografia freudiana. Em Reich, nos últimos anos da década de 1920 e início dos anos 1930, desemboca numa crítica radical à estruturação social capitalista e, mais particularmente, às instituições responsáveis pela formação sexual do homem: a família, a escola e as entidades religiosas.

Segundo essa perspectiva, as dificuldades neuróticas eram produzidas socialmente e poderiam ser, em boa parte, evitadas a partir de transformações sócio-culturais que implicassem modificações no campo da sexualidade. Assim, por exemplo, no livro Psicologia de massa do fascismo (Reich, 1933/1974) - obra publicada no ano da ascensão de Hitler ao poder na Alemanha, 1933, e que procura entender por que boa parte do proletariado alemão, contra os seus próprios interesses de classe, apoiou o partido nazifascista (Albertini \& Watrin, 2004; Ramalho, 2001) a repressão sexual é vista como uma espécie de matriz que prepara o indivíduo para a aceitação das demais repressões. Em termos mais específicos, a inibição sexual tenderia a gerar pessoas impotentes diante da vida e, em conseqüência, potencialmente aderentes a ideologias autoritárias, como a nazi-fascista, que, sob o manto da moralidade, aliava proteção e satisfação de impulsos sexuais e destrutivos. Com essa compreensão, a revolução sexual proposta por Reich teria efeitos que ultrapassariam, em muito, a esfera da luta pelo direito ao amor sexual; ela se insere num amplo projeto de transformação das estruturas sociais e humanas. 
Deve-se registrar que essa direção, de aposta na prevenção por meio de transformações sociais, de maneira alguma encontrou eco na produção freudiana da década de 1920. Em sentido contrário ao assumido por Reich, trabalhos de Freud, como $O$ mal-estar na civilização (1930/1974), vão sustentar que a neurose é uma condição inevitável da vida civilizada; na verdade, o preço pago para a construção da civilização.

Além da atividade na Clínica Psicanalítica de Viena, caracterizada pelo atendimento à população pobre, Reich, buscando uma atuação de caráter mais preventivo, fundou, em 1928, também em Viena, a Associação Socialista para Consulta e Investigação Sexual. Essa entidade - que contava com a participação de psicanalistas como Annie Angel, Edmund Bergler e, sua primeira mulher, Annie Reich, oito médicos e um advogado - criou seis centros de aconselhamento espalhados por bairros de Viena. No livro People in Trouble (Reich, 1953/1976), assim o autor recorda o início dos trabalhos:

\begin{tabular}{|c|}
\hline $\begin{array}{l}\text { Espalhamos a notícia de que sexólogos } \\
\text { especialistas tinham formado uma } \\
\text { organização para fornecer, em vários bairros } \\
\text { de Viena, conselhos gratuitos sobre } \\
\text { problemas sexuais, educação de crianças e } \\
\text { higiene mental em geral [...] Foram dadas } \\
\text { palestras sobre higiene sexual, as causas e os } \\
\text { possíveis remédios para as dificuldades } \\
\text { emocionais. A sociedade assumiu a posição } \\
\text { de que a miséria sexual era causada, } \\
\text { essencialmente, pelas condições enraizadas } \\
\text { na ordem social burguesa e de que ela não } \\
\text { poderia ser removida inteiramente, mas que } \\
\text { podia ao menos ser aliviada com a ajuda às }\end{array}$ \\
\hline
\end{tabular}

Segundo Reich (1953/1976), logo os centros ficaram superlotados, e as principais atividades neles desenvolvidas eram o aconselhamento individual, o fornecimento de informações sobre métodos contraceptivos e as palestras sobre sexualidade de acordo com os princípios da Economia-Sexual denominação que Reich, progressivamente, passa a empregar para se referir à sua abordagem. Boa parte da procura era feita por mulheres com gravidez indesejada; nesses casos, a orientação era privilegiar o estado emocional da mulher e, muitas vezes, ocorria o encaminhamento para médicos que, sem autorização legal, faziam o aborto. Sobre a orientação socialista dessa Associação, deve-se pontuar que Reich, desde 1927, era membro do Partido Comunista Austríaco e, em 1929, publicou o livro Materialismo Dialético e Psicanálise (1929/1977).
Para os objetivos deste trabalho, um trecho muito esclarecedor de People in Trouble (Reich, 1953/1976) é aquele em que o autor aborda os aspectos inovadores dos centros de aconselhamento e, principalmente, reivindica o crédito por ter sido o primeiro a introduzir o tema da sexualidade de crianças e adolescentes no campo da higiene mental. Segundo o entendimento reichiano do período, seria possível alcançar efeitos preventivos a partir de orientações sobre a forma de lidar com a sexualidade de crianças e adolescentes. Nas palavras do autor:

nós integrávamos os problemas das neuroses, distúrbios sexuais e conflitos do dia-a-dia. Também era novidade atacar a neurose mais pela prevenção do que pelo tratamento. Isto dependia, basicamente, da forma de se conduzir a sexualidade em crianças e adolescentes. Neste ponto, desejo reivindicar prioridade e total responsabilidade para esta introdução à teoria da economia sexual [...] Até então, nenhuma atenção a esta esfera central da higiene mental havia sido dada (p. 108). [itálicos originais]

Ao pesquisar a perspectiva preventiva presente na obra reichiana, um domínio que não pode deixar de ser iluminado é o da educação. De acordo com a nossa apreciação, após 1927, a abordagem desse autor, afastando-se cada vez mais da orientação freudiana do período e adotando a noção de auto-regulação (Bellini, 1993) como eixo, vai investir massivamente na educação, em especial na educação infantil. De forma coerente com toda a elaboração teórica em curso, o foco da análise reichiana vai priorizar a esfera da educação sexual. (Albertini, 1994; Matthiesen, 2005).

Um escrito paradigmático desse foco é Sobre o onanismo (Reich, 1929/1980). Nesse texto, é possível encontrar orientações a respeito de como o educador deve proceder ao se deparar com a masturbação infantil. Vejamos, a título de ilustração, uma passagem:

Que fazer quando um menino de dois anos brinca com seu membro? Deixe que o menino se masturbe tranqüilamente. Normalmente, o onanismo aparece pela primeira vez nessa idade. Proibir o onanismo poderia unicamente lançar as bases para sucessivos transtornos sexuais, e devido ao sentimento de culpa que acompanharia o menino quando ele começasse a se masturbar, se obteria justamente o resultado oposto, ou seja, que o menino se masturbaria com muito maior freqüência, já que o sentimento de culpa, o medo e a 
contrariedade aumentam a excitação sexual (1929/1980, p. 37-38). [itálicos originais]

Nesse mesmo trabalho, agora discutindo a masturbação no caso do adulto, Reich observa que ela não deve substituir a relação sexual. No seguinte trecho, com manifesta perspectiva higienista, essa visão aparece de forma clara: "Não é higiênico, de um ponto de vista sexual, praticar reciprocamente o onanismo sem uma relação sexual normal, porque a excitação é maior que a satisfação lograda" (p. 34).

Nesta altura do nosso estudo, algumas ponderações precisam ser formuladas. Deve-se notar que a atitude de Reich frente à masturbação foi muito diferente da defendida pelo movimento de higiene mental. Enquanto este se posicionou, contundentemente, contra essa prática sexual - Costa (1980), Foucault (1980) e Patto (2002) Reich a compreendeu como uma atividade integrante do desenvolvimento sexual normal e, com esse entendimento, escreveu e se posicionou, de forma incisiva, contra a repressão da mesma. Além da divergência frente à forma de encarar a masturbação, pode-se dizer que as idéias reichianas vinculadas ao domínio sexual têm, em geral, um conteúdo oposto ao propagado pelo higienismo, posto que este dava sustentação à moral sexual do período, enquanto Reich a combatia.

Porém, é necessário observar que Reich constrói uma obra marcada pela busca de intervenção social, com escritos claramente posicionados, sobretudo no que se refere ao domínio das normas que regulam o comportamento sexual. Acontece que essa postura, de forma inevitável, pisa no delicado terreno das escolhas individuais sobre as diferentes maneiras de se conduzir sexualmente. Assim, por exemplo, ao afirmar a superioridade da relação sexual em comparação à masturbação mútua, ainda que fundamentado em argumentos de sua abordagem teórica, ele contribui para que determinada prática sexual seja considerada mais sadia do que outra, e não para uma perspectiva que promova a diversidade nessa área. Cabe ainda registrar que Reich, apesar de defender os direitos dos homossexuais, em termos do desenvolvimento psicossexual, considerou a orientação heterossexual como superior à homossexual. Sobre o tema, consultar o tópico A propósito da homossexualidade, no livro $O$ combate sexual da juventude (Reich, 1932/1990).

Em 1930, procurando maior inserção no movimento de transformação social, Reich mudou-se para Berlim e filiou-se ao Partido Comunista Alemão. No ano seguinte, fundou a Associação Alemã para uma Política Sexual Proletária, a Sexpol, organização ligada ao Partido Comunista. Entusiasmado, registrou a amplitude do movimento na cidade:
Quando fui para Berlim, discursei em reuniões de massa perto de - não sei - quatro ou cinco vezes por semana. Tive reuniões com duas e três mil pessoas. Havia reuniões em que padres católicos tinham que responder a perguntas sobre problemas de higiene mental, etc. Era extraordinário. Não havia movimento organizado em Viena, mas em Berlim havia cerca de cinqüenta mil pessoas na minha organização no primeiro ano (Higgins \& Raphael, 1979, p. 82/83).

Numa apreciação global, pode-se dizer que a Sexpol deu continuidade ao trabalho desenvolvido em Viena pela Associação Socialista para Consulta e Investigação Sexual, mas também transformou significativamente o seu rumo. Em vez de clínicas de aconselhamento e informação sexual, agora a proposta era politizar a questão sexual e vinculá-la profundamente à revolução comunista. No livro $O$ Combate Sexual da Juventude (Reich, 1932/1978), espécie de material norteador da Sexpol, a título de ilustração, vários exemplos da articulação entre a luta contra o capitalismo e as modificações almejadas no domínio sexual da cultura poderiam ser citados. Vejamos o seguinte:

As condições fundamentais de uma autoregularização da vida sexual poderão dar-se no capitalismo? Não, porque a educação sexual capitalista destrói sistematicamente a capacidade de satisfação sexual, e o processo de trabalho capitalista, de exploração desenfreada e de cadências infernais, destrói as forças corporais (p. 93).

Deve-se registrar que esse tipo de análise de cunho marxista não se mantém nos escritos reichianos a partir de meados dos anos 1930. Em termos concretos, vale lembrar que em 1933, depois de uma série de atritos com a direção stalinista do Partido Comunista Alemão, Reich é expulso e, a partir dessa data, afasta-se de qualquer participação política partidária. Em 1946, publica nos Estados Unidos, para onde havia imigrado em 1939, uma edição revisada e aumentada do livro Psicologia de massa do fascismo (Reich, 1946/s.d.), na qual o enfoque marxista da obra original, de 1933, é sensivelmente atenuado.

Se há essa dinâmica conceitual na trajetória reichiana, o mesmo não ocorre com relação à meta profilática. Pode-se afirmar que esta, além de mantida, é até ampliada. Um exemplo disso é o fato de que, nos últimos anos de sua vida, enquanto o atendimento clínico individual passa a ser visto de forma crítica, dadas as suas limitações no que diz respeito à 
orientação preventiva, o investimento nos cuidados com a criança ocupa progressivamente maior espaço nos escritos e propostas de intervenção. Esses cuidados incluíam medidas preventivas com a gestante, o parto e os primeiros anos de vida. (Reich, 1950/1976). Sobre essa direção, na entrevista a Eissler, Reich foi enfático:

quero que compreenda que a terapia individual não vale a pena. Não vale a pena. $\mathrm{Ah}$, sim, para fazer dinheiro e ajudar aqui e ali, vale a pena. Mas do ponto de vista do problema social, do problema da higiene mental, não vale a pena [...] Só as crianças valem a pena. É necessário recuar até o protoplasma não afetado (Higgins \& Raphael, 1979, p. 55). [itálicos originais]

Gostaríamos, aqui, de chamar a atenção para a linguagem utilizada por Reich em seus escritos. Estamos nos referindo sobretudo ao emprego de enfoques e termos que evocam a prática médica na área da saúde pública. Vejamos dois exemplos.

No âmbito das propostas de técnica analítica por ele formuladas, ao explicar as fases da Análise do Caráter, afirma: "No trabalho analítico é preciso distinguir duas partes: a recuperação do paciente e a sua imunização, tanto quanto esta é possível no decurso do tratamento" (1933/1995, p.33). [itálicos originais]

Sobre a atividade de prevenção da neurose, tece a seguinte comparação:

A situação exigia medidas sociais lúcidas e amplas, visando à prevenção das neuroses. Os princípios e os meios pelos quais essas medidas seriam aplicadas podiam, é claro, decorrer da experiência adquirida com os pacientes individuais, da mesma forma que se fazem esforços para combater os flagelos com base nas experiências adquiridas com os indivíduos contaminados. A varíola é evitada pela vacinação imediata. As medidas necessárias para prevenir as neuroses apresentam uma imagem obscura e assustadora. Mesmo assim, não podem ser contornadas. A única probabilidade de êxito está em destruir a fonte da qual brota a miséria neurótica (1942/1978, p. 171).

\section{CONSIDERAÇÕES FINAIS}

De acordo com os dados desta pesquisa, duas linhas de entendimento a respeito da participação de
Reich no cenário científico-cultural da primeira metade do século passado se impõem.

A primeira associa Reich ao movimento de higiene mental e é sustentada pelos seguintes argumentos: o próprio Reich se viu como um integrante desse movimento e, mais do que isso, como um introdutor de novas orientações no mesmo. Essas orientações, ligadas ao campo da prevenção, podem ser sintetizadas em duas asserções básicas: a) a neurose é uma doença de massas gerada por determinado contexto social e que, além de tratada, pode ser prevenida; b) o trabalho de prevenção dessa enfermidade deve privilegiar a maneira como a cultura lida com o tema da sexualidade, principalmente quanto a crianças e adolescentes.

A nosso ver, é possível concordar com Reich se forem consideradas a perspectiva preventiva presente em sua obra, a linguagem de cunho higienista adotada e a orientação voltada à discussão das normas sociais assumindo determinada diretriz cultural como a mais saudável. Pode-se afirmar que esse modelo como um todo revela a atuação de um médico que, imbuído de preocupações sanitárias na área da saúde mental, procurou higienizar a cultura de seus males, principalmente no campo da sexualidade.

Entretanto, se repararmos no conteúdo de suas idéias e nas filiações estabelecidas, ou seja, a forma particular como Reich procurou realizar o seu projeto preventivo, dificilmente poderemos associá-lo ao movimento de higiene mental. Em termos mais específicos, enquanto o movimento higienista, a fim de realizar o seu ideal profilático, associava-se a correntes de pensamento que produziam um "saber", em última instância, mantenedor da ordem social - caso da eugenia, que, aliando reducionismo biológico e racismo, produzia um discurso justificador das desigualdades sociais -, Reich, ao contrário, buscou alcançar sua meta preventiva atribuindo responsabilidade a essa ordem social e atuou no sentido de promover profundas alterações na mesma. Tal orientação fundamenta-se, de forma dissonante em relação a Freud, na concepção de que a neurose seria uma doença de massas, produto de uma cultura enferma, e que poderia ser prevenida por meio de determinadas transformações sociais. Com essa concepção, além de elaborar um vasto material escrito, organizou e liderou projetos de intervenção prática, como a Associação Socialista para Consulta e Investigação Sexual, em Viena, e a Associação Alemã para uma política sexual proletária, a Sexpol, em Berlim.

Enfim, em função do conjunto específico de critérios que se adote, pode-se associar ou não Reich ao movimento de higiene mental. De todo modo, é preciso ter em mente que sua atuação no campo da higiene 
mental foi extremamente peculiar. Trata-se de um autor não-eugenista, que militou em partidos comunistas e que, ao conceber a neurose como uma doença de massas, buscou prevenir a sua ocorrência investindo fortemente em transformações sócio-culturais.

\section{REFERÊNCIAS}

Albertini, P. (1994). Reich: história das idéias e formulações para a educação. São Paulo: Ágora.

Albertini, P. (2005). Reich discorda de Freud: uma crítica ao "malestar na cultura". Em P. Albertini (Org.), Reich em diálogo com Freud: estudos sobre psicoterapia, educação e cultura (pp.1138). São Paulo: Casa do Psicólogo.

Albertini, P. \& Watrin, J. P. S. (2004). Reich e a psicologia de massa do fascismo: aspectos históricos e educacionais. Comunicações: Revista do Programa de Pós-graduação em Educação da UNIMEP, 11(1), 113-122.

Bellini, L. M. (1993). Afetividade e cognição: o conceito de autoregulação como mediador da atividade humana em Reich $e$ Piaget. Tese de Doutorado Não-Publicada, Programa de PósGraduação em Psicologia Social, Instituto de Psicologia, Universidade de São Paulo, São Paulo.

Boarini, M. L. (2003). Higienismo, eugenia e a naturalização do social. Em M. L. Boarini (Org.), Higiene e raça como projetos: higienismo e eugenismo no Brasil (pp.19-43). Maringá: Eduem.

Costa, J. F. (1980, $3^{\mathrm{a}}$ ed.). História da psiquiatria no Brasil: um corte ideológico. Rio de Janeiro: Campus.

Costa, J. F. (1984). Violência e psicanálise. Rio de Janeiro: Graal.

Desviat, M. (1999). A reforma psiquiátrica (V. Ribeiro, Trad.). Rio de Janeiro: Fiocruz.

Foucault, M. (1980, $4^{\mathrm{a}}$ ed.). História da sexualidade: I - A vontade de saber (M. T. C. Albuquerque \& J.A.G. Albuquerque, Trads.). Rio de Janeiro: Graal.

Freud, S. (1974). Moral sexual 'civilizada' e doença nervosa moderna. (J. Salomão, Trad.). Edição Standard brasileira das obras psicológicas completas de Sigmund Freud (Vol. IX, pp.187-208). Rio de Janeiro: Imago. (Original publicado em 1908).

Freud, S. (1974). O mal-estar na civilização (J. Salomão, Trad.). Edição Standard brasileira das obras psicológicas completas de Sigmund Freud (Vol. XXI, pp. 81-171). Rio de Janeiro: Imago. (Original publicado em 1930)

Higgins, M. \& Raphael, C. (Orgs.) (1979). Reich fala de Freud (B. S. Nogueira, Trad.). Lisboa: Moraes. (Original publicado em 1967)

Laplanche, J. \& Pontalis, J. C. (1983). Vocabulário da psicanálise (P. Tamen, Trad.). São Paulo: Martins Fontes. (Original publicado em 1967)

Matthiesen, S. Q. (2005). Educação de educadores: pressuposto psicanalítico ou utopia reichiana? Em P. Albertini (Org.), Reich em diálogo com Freud: estudos sobre psicoterapia, educação e cultura (pp.89-106). São Paulo: Casa do Psicólogo.
Mira y Lopes, E. (1961). Guia de saúde mental: normas práticas de higiene psíquica. Rio de Janeiro: José Olympio. (Original publicado em 1956).

Patto, M. H. S. (2002). Freud e a pedagogia. Em L. Macedo \& B. A. Assis (Orgs.), Psicanálise e pedagogia (pp.145-157). São Paulo: Casa do Psicólogo,.

Ramalho, S. (2001). Psicologia de massa do fascismo: Reich e o desenvolvimento do pensamento crítico. Dissertação de Mestrado Não-Publicada, Programa de Pós-Graduação em Psicologia Escolar e do Desenvolvimento Humano, Instituto de Psicologia, Universidade de São Paulo, São Paulo.

Reich, W. (1974). Psicologia de massa do fascismo (J. S. Dias, Trad.). Porto: Escorpião. (Original publicado em 1933)

Reich, W. (s/d). Psicologia de massa do fascismo (M.G. Macedo, Trad.). São Paulo: Martins Fontes. (Original publicado em 1946).

Reich, W. (1976). Children of the Future. In W. Reich (Ed.), Children of the future: on the prevention of sexual pathology (pp. 5-21). New York: Farrar, Straus \& Giroux. (Original publicado em 1950).

Reich, W. (1976). People in trouble. New York: Farrar, Straus \& Giroux. (Original publicado em 1953).

Reich, W. (1977, $3^{\text {a }}$ ed.). Materialismo dialético e psicanálise (J. J. M. Ramos, Trad.). Lisboa: Presença. (Original publicado em 1929).

Reich, W. (1978). O combate sexual da juventude (A. Fontes, Trad.). Lisboa: Antídoto. (Original publicado em 1932).

Reich, W. (1978). A função do orgasmo: problemas econômicosexuais da energia biológica (M. G. Novak, Trad.). São Paulo: Brasiliense. (Original publicado em 1942).

Reich, W. (1980). Sobre o onanismo (S. Moretzohn, Trad.). Em A. Reich, Se teu filho pergunta (pp. 31-38). Rio de Janeiro: Espaço PSI. (Original publicado em 1929).

Reich, W. (1990). Pasión de juventud: una autobiografia, 18971922 (J. Balderrama, Trad.). Barcelona: Paidós.

Reich, W. (1995, $2^{\mathrm{a}}$ ed.). Análise do caráter. (M. L. Branco, \& M. M. Pecegueiro, Trads.). São Paulo: Martins Fontes. (Original publicado em 1933).

Rosen, G. (1994). Uma história da saúde pública (M. F. S. Moreira \& J. R. A. Bonfim, Trad.). São Paulo: HUCITEC/UNESP; Rio de Janeiro: ABRASCO. (Original publicado em 1958).

Roudinesco, E. \& Plon, M. (1998). Dicionário de psicanálise (V. Ribeiro \& L. Magalhães, Trads.). Rio de Janeiro: Jorge Zahar.

Schwarcz, L. M. (1993). O espetáculo das raças: cientistas, instituições e questão racial no Brasil, 1870-1930. São Paulo: Companhia das Letras.

\footnotetext{
Endereço para correspondência: Paulo Albertini. Instituto de Psicologia da Universidade de São Paulo, Departamento de Psicologia da Aprendizagem, do Desenvolvimento e da Personalidade, Av. Prof. Mello Moraes, 1721, Cidade Universitária, Cep 05508-900, São Paulo-SP.E-mail: palbertini@usp.br
} 